\title{
Breve aproximación al fenómeno social de la mara: de las violencias al riesgo ${ }^{1}$
}

\author{
Rafael Tarifa Ortiz \\ Alumno del Programa de Doctorado en Antropología \\ Universitat Rovira i Virgili \\ rafael.tarifa@estudiants.urv.cat
}

Resumen: El carácter transnacional de las maras deriva del flujo migratorio que conlleva el acelerado proceso de globalización. El factor migratorio - que a nivel individual puede conllevar un serio desajuste del contexto familiar del migrante-, la desubicación de los jóvenes y el consecuente "duelo migratorio" dotan a estas organizaciones juveniles centroamericanas de una naturaleza que les permite perpetuarse en el tiempo y extenderse con facilidad. La difusión, planificada o no por las organizaciones, pero sí regulada por estas, se lleva a cabo estableciendo pequeñas delegaciones (clicas) a través de jóvenes inmigrantes líderes de estas agrupaciones en sus paises de origen. Estas agrupaciones, para mantener su estructura, necesitan generar entre sus miembros una fuerte cohesión; con este fin las organizaciones mareras generarán una identidad colectiva que nacerá de un creativo y elaborado armazón simbólico.

Palabras clave: maras, migración, culturas juveniles, sociedad del riesgo, bandas.

Abstract: The transnational character of the "maras" derives from the migratory flow that comes with accelerated globalization. Individually, migratory factors can lead to a serious imbalance in the context of the migrant family and the dislocation of the young, and the consequent migratory conflict will change Central American youth organizations in a way that allows them to spread easily. Whether these organizations plan diffusion or not, they are nevertheless regulated by the setting up of small delegations (clicas) by the immigrant youth leaders of these groups in their home countries. Such groups need to maintain and generate a strong structural cohesion among their members, and to this end the "mareras" organizations succeed in generating a collective identity based on a creative and elaborate symbolic foundation.

Keywords: maras, migration, youth cultures, risk society, gangs.

1. El texto forma parte de mi trabajo de fin de Máster en Antropología Urbana (URV). Este artículo no podría haberse llevado a término sin el apoyo del Dr. Joan J. Pujadas Muñoz, que prestó su orientación en la elaboración de ese proyecto, ni los consejos recibidos por parte del Dr. Jaume Vallverdú Vallverdú en la redacción final del presente documento. 


\section{Introducción}

Este artículo constituye una síntesis que aborda el fenómeno social de las organizaciones juveniles centroamericanas conocidas como maras. Se trata de una reflexión genérica sobre estas agrupaciones que enmarca sus acciones dentro de la teoría de la sociedad del riesgo (Beck, 1986) y el concepto de modernidad líquida (Bauman, 2000). Esboza el modelo de organización, estructura y prácticas de estos grupos en América Central para finalmente trasladar al lector la importancia capital que adquiere implementar en nuestro país políticas públicas dirigidas a la integración de los jóvenes inmigrantes latinoamericanos a fin de prevenir la extensión del fenómeno.

En el ámbito académico de las ciencias sociales y en concreto de la antropología social, abrirse a la investigación de las organizaciones juveniles no es algo nuevo si tenemos en cuenta el corpus principal de trabajos realizados por el Departamento de Sociología de la Universidad de Chicago entre 1920 y 1930. Con la aportación inestimable y ejemplar de la denominada posteriormente Escuela de Chicago, nació la sociología urbana, que estudia las estructuras, los procesos, los cambios y los problemas derivados de la vida social en las urbes. El conocimiento generado por sus miembros se elaboró en un contexto socioeconómico donde el laissez faire era el principio que regía la política del momento, con sus consecuentes y conocidos efectos sociales no deseados (marginación, aumento de la criminalidad, etc.). Se trata de un panorama que no dista mucho del presente, si obviamos los matices que aporta la época actual. La ciudad como a Robert Ezra Park (1864-1944), una de las figuras más representativas de esa escuela y creador del concepto de ecología urbana, se muestra como un auténtico laboratorio social, donde un período de expansión económica genera una gran bolsa de inmigración y adosado a esta, de matute, sin tenerlo previsto se han introducido las organizaciones juveniles centroamericanas.

Los miembros del Departamento de Sociología de Chicago, fundado por Small en 1892, concedían importancia al medio social y adoptaban una perspectiva ecológica. La desviación juvenil no estaría motivada por una conducta patológica, sino que vendría condicionada por un contexto social que favorecería la emergencia de la delincuencia. Esta relación se hacía evidente debido a la ausencia de una red institucional que sostuviera a la población cuando quedaba al margen del reparto de beneficios que conllevaba la actividad económica. Los 
autores chicaguenses perseguían a través de la ciencia mejorar las condiciones sociales, "exorcizar" la situación de orden alterada y los conflictos a través de la acción humana construyendo otro orden social mediante la reforma del existente.

El Departamento de Sociología de Chicago empleó la investigación científica para generar un marco de comprensión que facilitase el desarrollo de políticas sociales dirigidas a mejorar las condiciones de vida de los ciudadanos. La influencia de la doctrina del llamado pragmatismo americano, corriente filosófica entre cuyos exponentes más reconocidos estuvieron a J. Dewey y G.H. Mead, ambos profesores en Chicago, condujo los trabajos del Departamento de Sociología chicaguense a la consecución de resultados elevando el nivel de sus investigaciones. Esta doctrina sigue siendo uno de los legados inmateriales presentes en el mundo académico e impregna todavía la labor de otros investigadores: "Tal vez la enseñanza más grande que podemos extraer de la Escuela de Chicago sea ese pragmatismo lleno de imaginación que nos permite ordenar y articular esas visiones fugaces y fragmentarias de los actores sociales urbanos" (Pujadas, 1992: 12). Este principio conformó la corriente filosófica que mayor impacto ha tenido en los Estados Unidos y se caracteriza, en lo referente a la ciencia, por su orientación empírica y la importancia de que las investigaciones científicas se valoren en función de los resultados que se obtengan de estas. Este artículo se inspira en el legado recibido por estos autores chicaguenses e intenta ser portador de ese espíritu innovador.

No puedo acabar esta introducción sin mencionar igualmente la labor que realizaron los investigadores de la Universidad de Birmingham a partir de los años sesenta. Desde su Centre for Contemporary Cultural Studies (CCCS) se llevaron a cabo una serie de investigaciones centradas en los estilos juveniles británicos. Continuando parte de la tarea iniciada por los chicaguenses, estos autores propondrán un nuevo modelo de análisis para el estudio de las culturas juveniles donde las pautas culturales que diferencian a este segmento de la población, esto es, su subcultura (Macionis y Plummer, 2011), pasarán a ser entendidas como práctica de resistencia. Esta oposición social será protagonizada por una parte de los jóvenes de la clase trabajadora, que rechazará y desafiará de esta forma la cultura hegemónica. De los estudios culturales insertos en esta corriente teórica de tradición marxista podríamos destacar las obras realizadas 
por dos de sus autores, Resistance Through Rituals (2005), de Stuart Hall, y Subcultura: el significado del estilo (2002), de Dick Hebdige.

\section{Las marasł estructura y organización}

La historia de la pandilla de la Calle 18 o Barrio 18 y la MS-13 o Mara Salvatrucha, ${ }^{2}$ que actualmente conforman lo que en el ámbito académico y mediático se han venido a denominar maras, nace en la ciudad estadounidense de Los Ángeles a mediados de la década de los sesenta en el caso de la primera y a inicios de los ochenta en el caso de la segunda. Sin embargo, los fundamentos socioculturales en los que se asientan y apoyan derivan de la reacción a la subordinación social sufrida en los Estados Unidos por los inmigrantes mexicanos a causa de su clase y condición étnica. Esta condición subalterna (Gramsci, 2000) provocó en los años cuarenta la emergencia a ambos lados de la frontera mexicano-estadounidense de un estilo juvenil (Feixa, 2008) transnacional. Las maras dieron continuidad y recrearon el legado cultural procedente tanto de la figura del pachuco 3 (1940-1960), joven de origen mexicano residente en las zonas fronterizas sureñas estadounidenses, como de la del cholo, ${ }^{4}$ que desde los años sesenta representa otra estación en el proceso cultural juvenil y transfronterizo que dio lugar a la aparición de las maras. Los jóvenes mareros adaptaron a sus fines, a su tiempo y a sus circunstancias concretas una estructura generada desde la marginalidad en un proceso que el sociólogo José Manuel Valenzuela ha venido a denominar pachoma (pa/pachuco, cho/cholo, ma/mara). En los límites de la sociedad industrial estas agrupaciones juveniles centroamericanas aprendieron de sus maestros mexicanos y chicanos el arte de la supervivencia urbana en la clandestinidad. Las maras han configurado toda una subcultura

2. Estas dos organizaciones están formadas por jóvenes de ambos sexos, de edades comprendidas entre los 9 y los 35 años y de origen salvadoreño, hondureño, guatemalteco o nicaragüense. Aunque pueden integrar a miembros de otras nacionalidades, su procedencia étnica es mayoritariamente centroamericana. Se estima que el número de miembros que componen ambas agrupaciones puede alcanzar en la actualidad los 120.000. 3. Esta figura juvenil definió una nueva identidad transnacional, ni mexicana ni estadounidense, como respuesta a su condición subalterna, creando las primeras agrupaciones juveniles latinas en suelo estadounidense.

4. Debido a la diversidad de significados que el término cholo posee dependiendo del contexto (país, etc.), hay que aclarar que en este trabajo no posee ninguna connotación negativa o peyorativa. En este artículo define un estilo generado por los jóvenes de origen mexicano que nació en los años sesenta en California (EE. UU.) y que se extendió ya en los ochenta de la frontera norte mexicana a las ciudades del centro de México. Este término fue adoptado por jóvenes que se apropiaron de ciertos elementos culturales del pachuco. 
que los líderes transmiten a sus iniciados, recreándola a lo largo de los Estados Unidos, México y Centroamérica y estableciendo todo un conjunto de símbolos, códigos de conducta y organización que se extiende y difunde con éxito allí donde se establecen estos grupos.

La mara, cuya unidad básica se denomina clica, extenderá su territorio apoyándose en esta célula de la organización, que tomará en su nombre los espacios públicos. Estas unidades deberán mantener bajo su control el territorio "conquistado" y, si es posible, ampliarlo. Este espacio simbólicamente definido y marcado (grafiti) conformará parte de la identidad de los jóvenes de ese grupo y deberá ser defendido del intento de apropiación por parte de otras pandillas. Si bien su estructura es jerárquica, no responde al modelo clásico vertical porque esta comparte la verticalidad con la flexibilidad que le proporciona la división en células (clicas). Las unidades básicas operan bajo el paraguas de la organización, esta es la encargada de tensionar y dar unidad a la red, pero las clicas ejercen el poder a nivel local y disponen de una autonomía y proximidad que les permiten tanto la adaptación continua como un conocimiento exhaustivo de los territorios. Estas células se apoyan mutuamente coordinándose a tra-

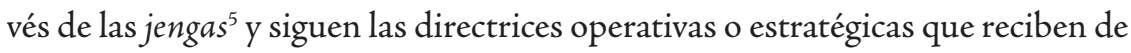
estas jefaturas nacionales; sin embargo, al disponer de una amplia autonomía, proporcionan a la organización una gran capacidad adaptativa. Habría que añadir a estos niveles un tercer escalón, en este caso no nacional sino internacional, que estaría compuesto por la Jefatura Supranacional, que conformaría el consejo, un espacio de coordinación entre las distintas jefaturas nacionales.

Estos grupos han evolucionado adecuando su organización a las políticas de represión aplicadas en el triángulo norte centroamericano (El Salvador, Honduras y Guatemala), respondiendo con una mayor violencia para seguir manteniendo su poder y el control del territorio. No han disminuido sus actividades ilegales y los líderes en prisión siguen dirigiendo sus agrupaciones; es decir, los efectos perseguidos - la erradicación de la violencia, que no se ha logrado - no han acabado con la organización marera y esta sigue operando a pesar del encarcelamiento masivo de sus miembros. La lógica de estas agrupaciones las lleva a defenderse contra lo que consideran una agresión ilegítima y reaccionan con mayor virulencia en sus acciones, adecuando a la par su estructura y organización a las necesidades del momento. Esta dinámica incrementa

5. Jefaturas nacionales que dirigen y coordinan varias clicas o unidades básicas (células) de la organización. 
la espiral de violencia en la que estas agrupaciones están inmersas, el ataque las cohesiona y fortalece como grupo; además, como les supone un coste económico añadido, han de aumentar cuantitativa y cualitativamente sus actividades ilícitas para conseguir un mayor volumen de ingresos que les permitan seguir atendiendo las necesidades económicas de sus miembros y de su organización. En este escenario se hace visible su vínculo con el narcotráfico y se incrementa el nivel de extorsión hacia la población que reside en sus territorios.

Respecto al liderazgo, hay que tener en cuenta que, aunque los mareros expresan que la toma de decisiones en la clica se lleva a cabo a través de una asamblea en la que cada miembro puede participar y contribuir con su opinión, el que estos puedan asistir a las reuniones ${ }^{6}$ y ser escuchados no implica una estructura horizontal o democrática dentro del grupo. Es más, esas reuniones son obligatorias y la falta de asistencia no justificada de alguno de sus miembros conlleva el castigo del infractor de esa norma, por lo que pueden acabar siendo más un instrumento de control y adoctrinamiento que un espacio para la toma de decisiones. La fuerte influencia del líder del grupo evidencia que el "discurso oficial" de los mareros y su insistencia en el carácter horizontal en la toma de decisiones están muy alejados de la realidad que se vive dentro de este tipo de agrupaciones. Como toda organización vinculada al crimen, la mara oculta su estructura para proteger a los líderes y la imagen que intentan difundir de una toma de decisiones asamblearia es mera propaganda. El encarcelamiento de algunos miembros ha posibilitado la observación de las conductas de estos jóvenes en un medio cerrado y los investigadores han podido constatar las relaciones de subordinación y sumisión que los miembros de estas agrupaciones establecen con sus jefes. El liderazgo existe y se ejerce diariamente tanto en el interior del grupo como en la comunicación que las bandas establecen con las autoridades carcelarias u organizaciones no gubernamentales, siendo los líderes los interlocutores de sus pandillas (Demoscopía, 2007).

En el interior de estas agrupaciones, el incumplimiento de las normas establecidas por el grupo conlleva una sanción. El recurso empleado para la corrección de las conductas no deseadas por la organización se basa en la utilización de la violencia física contra el miembro que rompe las reglas de juego establecidas. La violencia se impone y forma parte de las medidas que garantizan el

6. Los miembros de las clicas se reúnen periódicamente; a esa reunión la denominan mirin. 
mantenimiento de la disciplina interna. Pedro Gallego ${ }^{7}$ nos indica en su libro La mara al desnudo (2008) las reglas que los componentes de las maras de tipología centroamericana (MS-13 y Calle 18) deben cumplir una vez que los jóvenes han ingresado en estas agrupaciones. Aquí las reproduzco de nuevo por el interés que conlleva el grado de disciplina interna que estos grupos son capaces de alcanzar gracias a un sistema de normas que puede someter a sus integrantes a la coacción, al castigo físico y, en ocasiones, a una muerte certera si se incumplen:

Al 'brincarse' o ingresar en la mara, todos son advertidos de que no hay vuelta atrás, que se trata de un compromiso de por vida [... ]: si te tachas la placa ${ }^{8}$ del barrio, tu paga es la muerte; si hieres o matas a un hommie ${ }^{9}$ por cualquier razón no autorizada, tienes que hacerte responsable de lo que te toque. Si tratas de huir tu paga es la muerte; si por algún motivo insultas al barrio, se te da un chequeo ${ }^{10}$ y deberás limpiar chaqueta, ${ }^{11}$ si un hommie del barrio es muerto por un integrante de otra pandilla, se busca al hechor. ${ }^{12}$ Si no se encontrare, se le da pa' bajo ${ }^{13}$ a dos de la misma pandilla; desde que eres brincado al barrio, debes llevar tu placa tatuada; si te desertas del barrio tu paga es la muerte (Gallego, 2008: 95-96).

Todo este conjunto de normas revela el compromiso que adquieren los jóvenes una vez que han ingresado en estas agrupaciones. Pues bien, si el conjunto de reglas y sanciones se cumple y es más una realidad que un mito para infundir temor, nos encontraríamos ante un régimen interno brutal. Esta serie de instrucciones pondrían de manifiesto su draconiana normativa interna y destilaría un sistema de valores que legitima y promueve la violencia interpersonal e intergrupal. Sus reglas requieren un análisis en profundidad que sobrepasa las características de este artículo y reflejarían un código de conducta donde el te-

7. Sargento primero de la Guardia Civil y experto en maras centroamericanas.

8. Tatuaje donde se muestra el nombre de la mara. Esta marca puede componerse de números y/o letras que identifican a la organización (XV3, 18, MS, 13, etc.).

9. Miembro de la misma organización. En la literatura que aborda el tema aparece escrito en una gran variedad de formas (homie, homi, jomie, jami); entre ellos también se llaman hermanos o homeboy.

10. En este contexto significa castigo físico o paliza, aunque en otros puede significar el período en el que un aspirante demuestra su valor y coraje cuando quiere ingresar en la pandilla (brincado).

11. El infractor de la norma ha de limpiar su falta realizando una acción que es ordenada por el jefe de la clica.

12. $\mathrm{Al}$ autor del asesinato.

13. Se procede a la ejecución, se asesina. 
ror es norma. Se podría afirmar que en el interior de la mara se vive una dictadura donde, en pro del "interés colectivo", se justifica el asesinato como recurso para imponer justicia, tomar el control y obtener el poder. No se permitiría la disidencia, esta se concebiría como traición y se pagaría con la vida. El individuo que conforma la mara estaría inmerso en una comunidad regida por un código de normas que concibe al individuo como una pieza más del engranaje de su organización destinada a asegurar la vitalidad y la continuidad de esta. El marero no solo configura su identidad a través de la mara, el proceso va más allá. El joven que integra este tipo de agrupación no tiene valor por él mismo, son sus acciones, su contribución y pertenencia al grupo lo que le otorga "carta de ciudadano". Si lo abandona o traiciona, pierde ese estatus y por esta razón se le puede arrebatar todo (la vida). Junto a la supuesta solidaridad grupal y su discurso de protección comunitaria, la organización marera fomenta el control de sus miembros y la represión para asegurar su sometimiento.

\section{Género}

En una cultura abiertamente machista, estas agrupaciones juveniles se configuran como una plataforma para la liberación del rol tradicional de la mujer $y$ sus conflictos familiares al permitir su entrada en organizaciones desde las que se puede ejercer un poder (más imaginario que real) y dar una solución inmediata a los problemas que pueden estar sufriendo dentro de sus familias (abusos, malos tratos, excesivo control, necesidad económica, etc.). Dentro de estas agrupaciones las mujeres buscarán conseguir el espacio de socialización que necesitan y un reconocimiento que les proporcione seguridad, pero esa aspiración legítima y propia de compartir una imagen idealizada de la agrupación es ilusoria y se aleja completamente de la realidad cotidiana que tendrán que hacer frente en el interior de estas organizaciones:

La atracción que siente la joven mujer hacia la clica se relaciona con un fuerte componente afectivo-emocional: ella espera encontrar espacios de libertad, de reconocimiento de sus necesidades como mujer, afecto, amistad, respeto. Aspira a que sus jóvenes compañeros, que comparten con ella convicciones, creencias y el mismo estilo de vida, construyan relaciones de igualdad, relaciones paritarias, sin tomar en cuenta que el mundo de las pandillas también está impregnado de valores machistas, donde la violencia de sus hogares se 
reproduce al interior del grupo, e impiden el desarrollo como mujer que sueña con ser libre e igual al hombre (Martín, 2007: 174).

La posición que ocupan dentro de la agrupación es subalterna. Las maras, a pesar de esgrimir un discurso igualitario, reproducen los rasgos tradicionales de la cultura hegemónica en las relaciones de género. Esta particularidad cultural y la "debilidad" que los hombres atribuyen a ciertas actitudes que las mujeres presentan dentro de estas agrupaciones (mayor posibilidad de negarse a cometer asesinatos, confidencias a policías, etc.) pueden estar generando que las mujeres se afilien a la mara en estructuras auxiliares, subgrupos anexos conformados únicamente por mujeres, configurando pandillas femeninas que prestan una labor de apoyo al grupo matriz. Si forman pandillas mixtas (hombres y mujeres), habrá una diferenciación en los ritos iniciáticos a los que se sometan, en la posibilidad de tomar decisiones y en el nivel jerárquico. Una mujer no podrá acceder al liderazgo de este tipo de agrupación juvenil (mixta) aunque contribuya con su presencia y actividades en el grupo:

La violencia simbólica es también reproducida por ellos mismos, ya que los mismos procesos de dominación y exclusión son ejercidos por ellos en el interior de las maras. Si bien es cierto que hay fuertes lazos de solidaridad, también es cierto que la lealtad y el poder que tienen los líderes de los distintos grupos reproduce procesos de dominación. La situación de la mujer dentro de las pandillas es un ejemplo. En las maras se reproducen las formas de la violencia contra la mujer que en la sociedad se realizan de forma cotidiana (Martel, 2007: 124-125).

\section{Consumo y tráfico de drogas}

Pero estos grupos no solo resultan atractivos por cubrir en teoría sus necesidades afectivas, sino que se convierten en hábiles seductores al posibilitar a los jóvenes el acceso a la diversión y al consumo de drogas. Abordar este fenómeno sin tener en cuenta esta variable es no percibir el peso específico que adquiere este consumo en la vida de los jóvenes miembros de las maras. Las drogas se convierten en una vía de escape y diversión que perjudica la inserción en las sociedades que acogen a estos grupos, alimentando y conformando un cóctel de marginación, violencia y drogodependencia que acaba anulando las pocas posibilidades de inclusión de sus trayectorias personales en los contextos laborales 
y educativos. La necesidad de mantenerse alerta en los momentos de acción y de relajarse en los de diversión y distensión y la tolerancia, comprensión y complicidad del grupo con el consumo de drogas configurarán un marco ideal para que un joven, ya sea por desarraigo, por problemas familiares o por no tener más horizontes que el presente inmediato y la vida sin freno, llegue a generar una adicción a este tipo de sustancias.

El principal motivo de ingreso y permanencia en las maras salvadoreñas anotan varios estudios - es lo que sus miembros denominan 'el vacil', término del lenguaje popular que refiere a la búsqueda de diversión y entretenimiento. "A mí me gusta el vacil, nos metemos por eso", dice alguien, al igual que una buena parte de los mareros [...]. "El consumo era activo, todos los días todo el día, cada rato embalándose", se oye decir a cualquiera de sus representantes (Perea, 2007: 295-296).

Ciertamente, atracar, agredir y consumir se retroalimentan de uno y mil modos. El consumo es imposible sin el robo, la adicción demanda dinero; y al revés, las "vueltas" exigen una estimulación corporal que neutralice el miedo y la torpeza. Como lo expresa uno,"si no se roba no hay plata, si no hay plata no hay vicio, si no hay vicio no hay nada" (Perea, 2007: 297).

Aunque su adicción o la práctica del consumo fueran anteriores a su adscripción, la mara puede estar facilitando y fortaleciendo esta conducta. Los jóvenes pueden estar accediendo al observar en el grupo no solo una tolerancia a su adicción, sino una plataforma excelente que les facilita el acceso a las drogas y a la diversión asociada a ellas. Hay que tener en cuenta que el consumo no es únicamente el elemento que vincula las drogas con estas organizaciones de calle centroamericanas, ya que los estudios y las investigaciones que se han llevado a cabo señalan que una parte de las actividades de estas agrupaciones se orientan a una de las ramas del crimen organizado, el tráfico de drogas: "Asimismo, las autoridades policiales señalan la responsabilidad de algunas de las clikas en el control del comercio y de la distribución de drogas en sus respectivas zonas de influencias, las cuales se realizan en coordinación con redes del narcotráfico" (Cruz, 2006: 52). El comercio de drogas (narcomenudeo) se ha convertido en una de las actividades lucrativas de las maras. Según el estudio realizado por Demoscopía, S. A., en 2007, la participación del sector femenino marero en esta actividad económica ilícita es muy frecuente y la remuneración 
que obtienen las mujeres de sus actividades delictivas (robos, narcomenudeo) consiste en un pago con dinero efectivo (35\%) o con drogas (30\%). La obtención de este tipo de sustancias ilegales es considerada por las mareras como uno de los beneficios que reciben por pertenecer a este tipo de agrupación. De las investigaciones realizadas se puede inferir que este tipo de agrupaciones no solo toleran el consumo entre sus miembros, sino que convierten su comercio en fuente de ingresos a la vez que facilitan el acceso a las drogas a los jóvenes como medio de pago por sus actividades, con lo que promueven, por lo tanto, el mantenimiento de su consumo.

\section{La calle}

Todos los estudios coinciden en observar que este tipo de organización juvenil posee una clara orientación hacia el uso de espacios públicos. Entre las funciones que cumple el territorio encontramos tanto las de naturaleza simbólica como instrumental. El espacio público se convierte en un mapa de significados para los miembros de las maras, en un auténtico territorio simbólico debido a la fuerte vinculación (afectiva y psicológica) que establecen con él. El lazo de unión que establecen con el territorio proporcionará uno de los elementos que facilitará la construcción de su identidad grupal (Demoscopía, 2007. Capítulo II: 26). Los parques, las calles y sus esquinas constituirán los espacios públicos donde su presencia denota dominio, poder y control. Los muros, las paredes, se transformarán para ser marcadas con sus grafitis, definiendo fronteras simbólicas con los denominados placazos ${ }^{14}$. Las clicas se adueñan del espacio público marcándolo, es un acto simbólico de apropiación, el "documento" que otorga la titularidad de un espacio, el dominio sobre un territorio. Este espacio definido simbólicamente pasará a ser defendido por la mara que haya llevado a cabo su apropiación. El grafiti se convertirá en un mensaje a navegantes, en advertencia, en un límite que el resto de pandillas han de respetar al hacerse público mediante el símbolo el control del territorio. Además, con esta apropiación simbólica intentan fijar la subcultura de su grupo en la comunidad, situando a este en el entorno próximo de los jóvenes:

14. Pintada que realizan las maras en el inmobiliario urbano para marcar como propio un espacio público o enviar mensajes a otras pandillas. También en el argot marero placa puede significar tatuaje. 
A través de la función de la territorialidad la subcultura se enraíza en la realidad colectiva de los muchachos, que de esta manera se convierten ya no en apoyos pasivos, sino en agentes activos. La territorialidad es simplemente el proceso a través del cual las fronteras ambientales son usadas para significar fronteras de grupo y pasan a ser investidas por un valor subcultural. Ésta es, por ejemplo, la función del fútbol para los skinheads. La territorialidad, por tanto, no es sólo una manera mediante la cual los muchachos viven la subcultura como un comportamiento colectivo, sino la manera en que la subcultura se enraíza en la situación de la comunidad (Cohen, 1972: 26-27; citado en Feixa, 2008: 116).

Entre las funciones que desempeña el espacio público sobresalen las instrumentales por la importancia que el factor territorial reporta a estas agrupaciones. La calle pasará a ser un espacio de encuentro, recreativo, de captación, y les proporcionará la logística necesaria en caso de que se produzcan enfrentamientos con miembros de pandillas rivales, convirtiéndose a su vez en una fuente de ingresos derivada de la extorsión a la que someten a la población de las zonas sometidas a su control. El dominio de la zona por parte de las clicas y su permanente visibilidad en esta llevan a la captación de nuevos miembros. La apropiación del territorio conlleva su control, la visibilidad de los miembros de la clica en la zona se hace patente, notoria, la mara impregna el territorio con su presencia. La ocupación del espacio público no será baladí, ya que mediante esta presencia lograrán incrementar el número de miembros de sus agrupaciones, con lo que aumentará el número de simpatizantes y jóvenes interesados en formar parte de las maras. La defensa de las zonas que consideren bajo su dominio llevará a estas agrupaciones juveniles al enfrentamiento entre ellas. Cuando un pandillero ocupe con su presencia el territorio de otro grupo, será rápidamente expulsado de esa zona a través de la intimidación o la agresión. Su sola presencia será motivo de enfrentamiento y puede conllevar la muerte del marero. Para los miembros de estas agrupaciones, esas luchas por el control de los espacios públicos representan la base de su sustento económico, pues de su control dependerá el que puedan traficar con drogas o extorsionar a la población en él. 


\section{La presentación social del cuerpo}

El elemento identitario que mayor repercusión mediática ha tenido, junto a la violencia que han protagonizado estos grupos, es el tatuaje del marero, esa marca indeleble en la piel que se convierte en el relato biográfico del que lo porta. El símbolo se hace carne en los mareros, que trasladan y hacen visible la identidad grupal en sus cuerpos; sus miembros se sentirán orgullosos de convertir sus cuerpos en emblemas de su adscripción callejera, buscando sentir y apropiarse del poder de la organización. La identidad del grupo se construye, es dinámica y maleable, pero sus símbolos serán "eternos" (si la cirugía no interviene) en el cuerpo de sus miembros. El cuerpo del marero pasará a ser objeto, emblema de la agrupación, haciendo visible, carnal y física una identidad y una organización que no lo son. Estas marcas indelebles en los cuerpos de los pandilleros reflejan la fuerte influencia del conjunto de normas y valores del contexto social en el que estos se socializan. La mutación de la imagen social del pandillero está influida por el habitus (Bourdieu, 1972), es decir, por el conjunto de normas, valores y esquemas clasificatorios en función de los cuales los individuos actúan, piensan o sienten. Esta práctica corporal que el marero siente como emblema será percibida bajo la interpretación de los que no son miembros como un estigma, entrando su portador a formar parte de una categoría social no deseable y rechazada tanto por la población como por el resto de pandillas.

Las elecciones corporales de cualquier persona, mujer $\mathrm{u}$ hombre, alto o bajo, joven o viejo, siempre están influidas por el babitus in-corporado socialmente [...]. Aquellas prácticas corporales que las y los jóvenes viven y sienten como emblemas, se interpretan y se transforman en estigmas por los que los observan desde una perspectiva externa, como por ejemplo otros jóvenes que han elegido prácticas diferentes para sus cuerpos (Porzio, 2012: 90).

Esta modificación que sufre el cuerpo una vez que el joven pasa a formar parte de la mara es voluntaria, es el pandillero el que pedirá realizarse el tatuaje, pero no es libre. Esta práctica corporal está regulada por la organización, ya que ciertos tatuajes representarán la posición, el cargo o el estatus del individuo en el interior del grupo. Transformar el cuerpo y ser emblema de la mara es un acto que requiere la autorización de los líderes, que al permitirlo están reconociendo el mérito de este miembro y su éxito en las acciones encomendadas por el grupo a su persona. Estas "medallas" proporcionarán al pandillero una imagen social 
marcada por su adscripción y las actividades del grupo. El joven pandillero, al convertir su cuerpo en biografía, estaría mostrando tanto el reconocimiento obtenido del grupo como su estatus dentro de la organización (Demoscopía, 2007. Capítulo II: 29). Dentro de las agrupaciones juveniles mareras la identidad personal se diluye en la colectiva. Las pandillas, mediante el control del cuerpo y de la presentación social que sus miembros hacen de él, consiguen crear un sistema de dominación. Este control permite forjar una visibilidad que lleva estas organizaciones a alcanzar sus objetivos, ya que tal visibilidad no es fruto del azar, sino que se formula como desarrollo de una estrategia dirigida a alcanzar una serie de fines.

La idea de visibilidad constituye un útil conceptual más para entender los complejos procesos de interacción que configuran el ámbito de lo social y muy especialmente por lo que concierne a la presentación social del cuerpo. En nuestro contexto, visibilidad implica alguien que por unas razones concretas y con una estrategia determinada quiere hacer algo visible en una situación dada; implica también un medio donde esto se hace visible, un alguien a quien se quiere hacer visible esto y unas expectativas sobre esta visibilidad (Martí, 2012: 9).

Las maras han construido un sistema de dominación entre cuyos pilares se encuentra la visibilidad de la identidad grupal mediante la regulación de la presentación social del cuerpo de sus miembros. Esta puesta en escena no se agota con la transformación de sus cuerpos mediante la práctica corporal del tatuado, sino que incluiría también la comunicación no verbal. Estas agrupaciones juveniles centroamericanas han desarrollado un lenguaje gestual propio. Se trata de un lenguaje de signos de manos que es transmitido a sus miembros para que puedan identificarse y comunicarse entre ellos. A esta comunicación no verbal habrá que añadir el uso que los jóvenes mareros hacen tanto de su postura como del contacto visual. Las miradas sostenidas, el contacto visual persistente de los mareros, acaban convirtiéndose en un excelente instrumento de intimidación que ayuda a provocar inquietud en quien es objeto de esa mirada.

Entendemos por presentación social del cuerpo la manera consciente y voluntaria de disponer del cuerpo en vista a su interacción social, tanto mediante aquello que se hace en él, como también mediante aquello que hacemos con él. Por una parte, pues, estamos hablando de la imagen que queremos ofrecer 
del cuerpo a través de su cuidado personal, indumentaria y ornamentación, y el no menos importante recurso de las modificaciones corporales. Por otra, la presentación social del cuerpo tiene que ver con la gestualidad, las técnicas corporales y las conductas proxémicas (Martí, 2012: 8).

\section{Comunidades explosivas}

No se puede pasar por alto que los jóvenes que se integran en estas organizaciones no buscan únicamente un mayor acceso a las drogas o la tolerancia y la compresión de su adicción en el grupo, sino alcanzar en ellas lo que les ha sido negado o no han encontrado en sus comunidades. Una sociedad que ofrece falta de oportunidades laborales y educativas, violencia familiar, pocos espacios recreativos, autoritarismo, etc., configura un excelente terreno donde "plantar" las semillas-clicas, las células que iniciarán y extenderán la organización sobre el territorio. Si a estos ingredientes le sumamos la carencia de redes sociales y de organizaciones comunitarias que ejerzan de paraguas frente a la incertidumbre, la precariedad y la vulnerabilidad de los menos afortunados, tendremos no solo un terreno apropiado, sino el abono necesario para que la mara crezca con rapidez y fortaleza. Estas circunstancias que reflejan la fractura social no son exclusivas de los países centroamericanos o de una historia nacional concreta, pero sí de un proceso de urbanización acelerada, de factores sociales y económicos que desembocan en exclusión. La respuesta reactiva de los jóvenes será la formación de pandillas que suplan las carencias.

Las pandillas representan el esfuerzo espontáneo de los muchachos por crear una sociedad para sí mismos allí donde no existe ninguna adecuada a sus necesidades [... ]. Las costumbres e instituciones encargadas normalmente de dirigir y controlar no han logrado funcionar eficazmente en la experiencia del muchacho; lo cual está indicado por la desintegración de la vida familiar, la ineficacia de las escuelas, el formalismo y exterioridad de la religión, la corrupción e indiferencia de la política local, los bajos salarios y monotonía de las ocupaciones, el desempleo y la falta de oportunidades para una recreación satisfactoria. Todos estos factores entran en la imagen de la frontera moral y económica $y$, unidos al deterioro de la vivienda, la salubridad y otras condiciones de vida en los barrios bajos, dan la impresión de desorganización y decadencia generales. La pandilla funciona respecto de estas condiciones 
de dos maneras: ofrece un sustituto de lo que la sociedad no es capaz de dar y proporciona alivio a la supresión y al comportamiento desagradable (Thrasher, 1963: 32-33; citado en Hannerz, 1986: 52).

El riesgo permanente de la violencia estructural y los niveles de pobreza y desigualdad de ingresos que prevalecen en Centroamérica con independencia del ritmo de crecimiento económico fomentan el sentimiento de frustración de unos jóvenes a los que se insta al consumo y al disfrute a través de la publicidad, el cine y la televisión, ejerciendo sobre ellos la presión constante del mercado con sus mantras: "consume para ser feliz", "disfruta el momento”, etc. Los jóvenes integrantes de las maras no son extraños, no son los otros, sino nosotros, tal vez hijos no deseados de una sociedad que parece ir a la deriva, sin referentes, sin más metas que el disfrute de lo inmediato, del ahora o nunca, de la divinización de la juventud y el deseo. Son producto de las contradicciones de nuestra modernidad y sus expresiones violentas son en parte una consecuencia de las violencias (estructurales, simbólicas, etc.) que se han ejercido sobre el colectivo más vulnerable de todos, la infancia y la juventud. La violencia intrafamiliar, las políticas económicas injustas, la desigualdad social y económica, el desempleo, el subempleo..., van reduciendo las posibilidades de inserción de los más jóvenes y minando sus proyectos personales, que se centran en el presente ante la falta de horizontes. El andamiaje social deteriorado se fractura por los embates de la economía, la deserción de los políticos y una cultura que fomenta el individualismo y la competencia, no la solidaridad. Es lo intersticial de Thrasher, el espacio vacío entre la estructura social y los jóvenes: “También hay fisuras y fallas en la estructura de la organización social. La pandilla se puede considerar como un elemento intersticial en el marco de la sociedad, y el territorio pandilleresco como una región intersticial en el trazado de la ciudad" (Thrasher, 1963: 20; citado en Hannerz, 1986: 49). En las grietas y en el derrumbe de lo social nacen las maras, la nueva comunidad que atrae porque es visible, real y cercana. En ella se puede experimentar lo auténtico, la virtualidad no es su campo de acción. La virtualidad es el atributo que caracteriza en los países centroamericanos las políticas públicas de protección al menor y su plena integración social.

La extensión en nuestro país de las agrupaciones juveniles latinas y su versión más violenta, la mara centroamericana, podría tener su motor en las políticas públicas que, transformadas en planes y programas que intentan garantizar 
el derecho a la educación de todos los ciudadanos, la plena integración social de los inmigrantes o la protección menor, se acaban difuminando en la virtualidad del documento en pdf del boletín oficial de un ministerio o dirección general y no en la realidad que diariamente afecta a estos jóvenes. Si las políticas públicas que han de garantizar estos derechos quedan en una mera declaración de intenciones y no son respaldadas con presupuestos acordes a las necesidades que garanticen los recursos suficientes para este reto, la exclusión pasará factura no solo a los jóvenes, que la sufrirán a nivel personal, sino también al Estado, que verá como económicamente el coste asciende en otra serie de medidas que podrían haber sido minimizadas con una prevención que lleva a la eficiencia. No hay que olvidar que las agrupaciones juveniles se extienden con más facilidad y mayor rapidez allí donde la fractura social se hace más evidente. Por lo tanto, reduciendo esta fisura en la estructura social podremos prevenir, al menos en parte, los factores que generan un terreno propicio para la aparición de formas de sociabilidad que desvían a niños y adolescentes hacia un entorno y unos comportamientos que dificultan aún más la integración en la sociedad que los acoge.

Las maras en Centroamérica son comunidades reactivas que se nutren del producto de la pasividad institucional en la frontera de un sistema que relega a sus miembros y los margina. Estas organizaciones establecerán un poder que se asienta en una violencia inaudita, en un temor que se filtra tanto a nivel interno como externo y les garantiza el dominio simbólico del territorio y el control de la población y de sus miembros.

En una de sus obras, ${ }^{15}$ el sociólogo, filósofo y ensayista polaco Zygmunt Bauman nos muestra, guiados a lo largo de su narración por la metáfora de la fluidez, el cambio inducido por el poder económico en la sociedad moderna, una metamorfosis que nos conduce a lo que él denomina modernidad líquida, una nueva etapa de la humanidad que conlleva un cambio radical. Los antiguos soportes de seguridad en los que se sustentaba la sociedad se derrumban por los embates inmisericordes de un poder económico que ya no nada (como los sólidos) en el capitalismo industrial (modernidad pesada), sino que fluye, adaptándose a los cambios con una rapidez nunca antes lograda (instantaneidad derivada de la tecnología electrónica y/o digital), sin límites ni barreras que le pongan freno, bajo la forma del capitalismo financiero. Este cambio no solo 15. Modernidad líquida (2000). 
opera a nivel económico y político, sino que se traslada de la esfera pública a la privada, impactando en las lógicas y prácticas de las personas, que ahora conciben el mundo como un gran supermercado donde todo se compra y se vende, se usa y se tira. Los ciudadanos mutan en consumidores eternamente insatisfechos en búsqueda de nuevas experiencias, de productos con los que suplir su ansiedad constante de seguridad. Dependientes del consumo, del mercado, y libres para elegir entre la amplia variedad de la oferta, pero sin posibilidades de modificar su presente y planificar su futuro, que se presenta oscuro y lleno de incertidumbre, carecen de capacidad "transformativa" y, con ello, de la posibilidad de modificar las condiciones que les dominan. La precariedad, inestabilidad y vulnerabilidad se convierten en unas incómodas parejas de viaje de la modernidad líquida, marcando las condiciones de vida contemporáneas.

Pues bien, esta nueva situación fomenta que los ciudadanos con menores recursos (económicos y sociales) para afrontar esta ruta laberíntica en la que se ha convertido su vida busquen refugio en la comunidad, en comunidades que pueden estar unidas bajo la falsa ilusión de una identidad étnica, e intenten conseguir por unos momentos evadirse de la confusión y el continuo caos en los que están envueltos. Reaccionan y se aferran a una nueva comunidad tribal.

La difusión en todo el mundo de lo que Pierre Bourdieu ha llamado la política de la precarización' tiene iguales posibilidades de imponerse. Si el ataque contra la soberanía del Estado demuestra ser fatal y terminal, si el Estado pierde el monopolio de la coerción (que tanto Max Weber como Norbert Elias consideraron su rasgo más distintivo $y$, al mismo tiempo, el atributo sine qua non de la racionalidad moderna y del orden civilizado), esa situación no originará la disminución de la suma total de la violencia, incluyendo la violencia genocida; simplemente, la violencia será 'desregulada' y descenderá desde el nivel del Estado hasta el nivel (neotribal) de la 'comunidad' (Bauman, 2000: 204).

Las organizaciones mareras producen comunidades "explosivas" que utilizan la violencia para cohesionar a sus miembros y prolongarse en el tiempo, e intentan adueñarse simbólicamente del territorio (grafiti) para marcar fronteras entre el nosotros (comunidad imaginada) y los otros. Estas agrupaciones juveniles centroamericanas encontrarán el sustrato ideal en la falta de un marco institucional que haga frente al reto que supone proporcionar estabilidad y seguridad a los jóvenes. La influencia y el poder que las organizaciones mareras 
ejercen sobre estos jóvenes acaban desviando el impulso social de sus miembros hacia la violencia, el exceso, la coacción y la furia. Lejos de conseguir la liberación y la protección adecuadas, la mara los puede someter a la obediencia ciega al líder y a una carencia de horizontes que potencie la sensación (agravada por la situación socioeconómica) de ausencia de futuro.

En ausencia de un marco institucional de estructuras arbóricas' (para usar la metáfora de Deleuze/Guattari), la sociabilidad puede retornar a sus manifestaciones 'explosivas', extendiéndose 'rizomáticamente' y generando formaciones de diferentes grados de durabilidad, pero invariablemente inestables, conflictivas y sin fundamentos sólidos sobre los cuales basarse (salvo las apasionadas y frenéticas acciones de sus adherentes). Habría que compensar la inestabilidad endémica de las bases. Y la complicidad activa (voluntaria y compulsiva) de los crímenes que sólo una 'comunidad explosiva' puede exonerar y eximir del castigo sería la mejor candidata para llenar ese vacío. Las comunidades explosivas necesitan que la violencia surja y que siga existiendo (Bauman, 2000: 204).

\section{Análisis teórico y camino por recorrer}

La continua transformación y el éxito en su extensión de las maras, ese carácter dinámico resultado de la adaptación de estos grupos a los diferentes escenarios que tienen que hacer frente, nos lleva a utilizar para una mejor comprensión de este fenómeno social la metáfora de la "fluidez" de Bauman, esa cualidad que poseen los líquidos y los gases. La actual modernidad está inserta en una etapa donde los líquidos triunfan frente a los sólidos. Las medidas tomadas por los gobiernos centroamericanos no han contenido el fluir de las maras. Estas organizaciones han modificado sus formas para adecuarlas al territorio y las condiciones del momento. En el encuentro entre las instituciones del Estado (lo sólido de Bauman) y la mara, esta ha sabido fortalecerse filtrándose entre las grietas, los resquicios abiertos por la fractura social, para salir victoriosa del encuentro entre ambos, empapando al Estado en actos que van en contra de los acuerdos internacionales que promueven el cumplimiento de los derechos humanos.

Los fluidos se desplazan con facilidad. 'Fluyen,' 'se derraman,' se desbordan', 'salpican,'se vierten,' 'se filtran,' 'gotean,' 'inundan,' rocían,' chorrean,' 'manan', 'exu- 
dan'; a diferencia de los sólidos, no es posible detenerlos fácilmente — sortean algunos obstáculos, disuelven otros o se filtran a través de ellos, empapándolos-. Emergen incólumes de sus encuentros con lo sólidos, en tanto que estos últimos — si es que siguen sólidos tras el encuentro- sufren un cambio: se humedecen o empapan (Bauman, 2000: 8).

La respuesta gubernamental a la violencia juvenil en América Central no ha establecido una estrategia que lleve a una respuesta efectiva al fenómeno; las políticas de control y represión no han podido erradicar las causas que llevan a estos jóvenes a integrar este tipo de agrupaciones. Solo se han implementado las medidas coyunturales que pueden frenar temporalmente los efectos (Plan Mano Dura, Plan Súper Mano Dura, Operación Puño de Hierro, etc.), pero estas no proporcionan las condiciones necesarias encaminadas a conseguir de forma permanente que los jóvenes no se involucren en estas organizaciones violentas o puedan llegar a abandonarlas. Las mutaciones que este fenómeno social presenta en los países del triángulo centroamericano demuestran el carácter dinámico de las organizaciones mareras, la gran facilidad que poseen para adaptarse a entornos hostiles y la fortaleza que extraen de su aparente debilidad. La represión las lleva a otros países en busca de refugio y a medio plazo al control de ese nuevo territorio, al dominio del resto de pandillas, al aumento del número de integrantes, a un incremento de sus actividades delictivas y violentas; a una deriva que está transformando lo que fue una organización juvenil en una banda armada al servicio del crimen organizado:

Las pandillas juveniles californianas, surgidas a mediados de los noventa, están paulatinamente perdiendo las características claves que las definen como organizaciones pandilleras. Están dejando de ser organizaciones de adolescentes y pasando a organizaciones de adultos jóvenes; ya no ostentan su orgullo pandillero sino que lo ocultan; ya no defienden territorio geográfico sino a su organización y a sus negocios; eran abiertas en el reclutamiento pero ahora son extremadamente selectivas; sus relaciones ya no son periféricas al crimen organizado, sino que forman parte de éste; están abandonando los tatuajes, el caló, los graffiti, la mímica particular suya y ahora trabajan en la clandestinidad; han endurecido las reglas para evitar deserciones, llegando al extremo de un exterminio irracional contra sus propios ex camaradas. De la misma forma se observa que las pandillas tradicionales rápidamente evolucionan o 
a ser parte de aquellas o de bandas del crimen común u organizado (Andino, 2006: 70).

Ulrich Beck nos proporciona desde la sociología, con dos de sus obras, las columnas del marco teórico donde podremos ir encajando las piezas de una acción dirigida a la prevención. Con la primera, La sociedad del riesgo (1986), no tan solo nos da el "mapa meteorológico" de las tormentas a las que habremos de hacer frente, sino que a medida que nos describe la situación (presente y futura) nos muestra cómo hemos llegado a ella, así como las claves para navegar estos mares de incertidumbre de la denominada sociedad del riesgo. Narra a lo largo de sus páginas cómo, empujados por una fe inquebrantable en el progreso económico, hemos ido ocultando, negando e interpretando erróneamente los resultados que en forma de riesgos y amenazas producía la "maquinaria" industrial. Cómo desde el sistema científico-técnico y con el consentimiento y beneplácito de las autoridades políticas hemos sido incapaces de dar una respuesta acertada y a tiempo al reto que el proceso de modernización nos lanzaba, poniendo con ello en peligro el proyecto ilustrado de la modernidad.

No obstante, Beck, después de llevarnos al límite (con unas visiones cuasi apocalípticas), nos ofrece una visión positiva del proceso en el que estamos inmersos por el amplio abanico de posibilidades que el mismo desarrollo genera. El proyecto de la modernidad no está acabado, hemos de seguir configurándolo ayudándonos de una perspectiva más realista y consciente de la realidad política, huyendo de la ingenuidad y de las utopías, apoyándonos en la autocrítica, que se configura como principio básico para un desarrollo que tenga en cuenta no solo el normal afán de lucro de las empresas (ya que este está inserto en su propia naturaleza y es su motor), sino también el bien común. Un proyecto que ha de ser alcanzado a través del consenso de todos los agentes implicados (económicos, políticos, ciudadanía, etc.).

La modernidad desarrollada surgió para eliminar las limitaciones derivadas del nacimiento y permitir que los seres humanos obtuvieran mediante su propia decisión y actuación un lugar en el tejido social; pues bien, este objetivo empieza a tambalearse. El proceso de modernización genera como producto de su propio desarrollo nuevos riesgos, nuevas amenazas, obligando a revisar los pasos que se han dado y moviendo al científico implicado y a la ciencia a la ac- 
ción, apoyando esta en el pilar de una reflexión crítica sobre los fines, los medios y las consecuencias de este desarrollo (reflexividad).

Pero ¿cómo trasladar la teoría de la sociedad del riesgo al caso que se aborda en este artículo? Empleando la terminología de Beck, los efectos secundarios latentes de la recepción de una gran masa de inmigración empiezan a ser visibles. Estas nuevas amenazas toman forma y se manifiestan en las conductas violentas de agrupaciones juveniles formadas en su mayoría por adolescentes de origen latinoamericano en riesgo social. Desde una perspectiva que parta de la modernidad reflexiva, si queremos ser coherentes con los principios de esta, hemos de tener en cuenta todos los factores que entran en juego. Esto requiere adoptar una postura crítica pero constructiva que afronte las nuevas necesidades desde un campo de estudio que cruce los límites tradicionales entre las distintas disciplinas académicas, es decir, la colaboración y la interdisciplinariedad devienen en este proceso no solo necesarias, sino imprescindibles. Otra condición es recuperar el pensamiento social. Huir de una visión exclusivamente técnica y naturalista de los problemas requiere una investigación cualitativa, los números no transmiten significados, no contemplan las normas, la estructura ni la racionalidad que domina.

En este mar de la globalización nuestro país abrió, en busca de un nuevo El Dorado, sus puertos a la necesaria mano de obra que hizo posible el progreso económico, sin tener en cuenta la fortaleza de los diques (recursos educativos, sociales, etc.) que posteriormente exigiría la acogida de esa bolsa de inmigración. Esos nuevos ciudadanos convertidos por el sistema tecnocientífico en números, porcentajes y gráficos demostraban cuantitativamente que la imparable utopía del progreso económico se hacía realidad. Nuestra fe en el progreso se hacía carne. Pero ese desarrollo (demográfico y económico) tal vez debería haber ido acompañado de partidas presupuestarias que dotaran de robustez a los servicios públicos que hacen posible la integración y la igualdad de oportunidades en nuestra sociedad. Quizás, desde la racionalidad dominante esta necesaria adaptación conllevaba no tener en cuenta la dinámica perfecta, el equilibrio "divino" que el mercado conseguía gracias al espíritu rector de "la ley de la oferta y la demanda". Y al vencer la lógica de la producción de riqueza acabó imponiéndose la sociedad del riesgo.

Fieles a nuestra nueva religión y convencidos de que esta era la única y la verdadera, gracias al "milagro económico" experimentado durante los últimos años 
en nuestro país, nos dejamos guiar por nuestros pastores, que veían como las obras crecían en la tierra prometida a la par que sus beneficios. Los riesgos no eran contemplados, permanecían invisibles, ya que no se manifestaban. La crítica era considerada una herejía, fruto de almas descarriadas que no eran conscientes de los buenos frutos que nuestro mercado hacedor nos proporcionaba. Un mercado que ha irrumpido en el sistema educativo dañando los fundamentos que daban sentido a la formación: "La formación ha perdido su implícito luego, las líneas de sentido que la orientaban más allá de ella hacia la actividad profesional" (Beck, 1986: 247), convirtiendo el paso del sistema educativo al laboral en un camino lleno de incertidumbre y un criterio de descalificación, porque quienes no accedan a una titulación quedan excluidos del acceso a una ocupación. El trabajo, uno de los grandes ámbitos de seguridad en la época moderna, es cada día que pasa más un factor de preocupación que un medio por el cual sentirse identificado y valorado. En la senda hacia la organización marera cada vez hay menos desvíos y más atajos. Esa inestabilidad que nuestro sistema genera podría ser aprovechada por la organización de estas agrupaciones juveniles, que prometen protección, afecto y comprensión a los jóvenes, convirtiendo a la mara en su aliado y protector solidario.

Hay que tener en cuenta que, a pesar de que las acciones de estas agrupaciones se alejan por el momento en volumen y gravedad de las llevadas a cabo por sus homólogos del otro lado del océano, si no se desarrollan las intervenciones necesarias podríamos con el tiempo ver crecer cuantitativa y cualitativamente el fenómeno de las maras en nuestro territorio. Por decirlo al modo "beckeriano", el estado de latencia del fenómeno no puede ser visto como ausencia de riesgo y ha de ser afrontado como real. El centro de la conciencia de riesgo no reside en el presente, sino en el futuro. Las medidas que se tomen han de evitar y prever situaciones que lleven a conflictos sociales de difícil manejo.

En la segunda de sus obras, La sociedad del riesgo mundial (2008), el sociólogo alemán Ulrich Beck nos facilita un enfoque epistemológico que huye del relativismo y la estrechez de miras que han caracterizado la investigación al abordar el estudio de la realidad social. Abre el campo a la anticipación y, por lo tanto, a la previsión. Desde la perspectiva de la seguridad, esta anticipación nos permite manejar de forma eficaz y eficiente los riesgos que conlleva la emergencia en nuestro país de estas agrupaciones juveniles de carácter violento que se han extendido desde los EE. UU. a América Central, instalándose en España al 
calor de la inmigración de estos últimos años. Beck nos proporcionaría el marco teórico para un análisis histórico-empírico que tenga como objeto de estudio el fenómeno transnacional de las maras. La reflexividad de la incertidumbre y el momento cosmopolita que estamos viviendo nos conducen a un cambio de paradigma tanto en la sociedad como en las ciencias sociales que tengan como objeto el estudio de esta; las nuevas inseguridades no pueden ser controladas nacionalmente. Nada de lo que ocurre localmente puede ser considerado un mero acontecimiento circunscrito a un lugar, territorio o país determinado. Por ello, hemos de tener presente lo global, porque puede reproducirse en cualquier contexto local; nuestra mirada ha de ser transnacional (local y global al mismo tiempo). Estamos en un período de transformación de la sociedad que el autor conceptúa como sociedad del riesgo mundial: "[... en lo que atañe a la dinámica de los conflictos generados por el riesgo, la mirada nacional ha quedado superada. Es necesaria una mirada cosmopolita para entender la incidencia de la dinámica global en lo general y en lo particular, esto es, a escala nacional o local" (Beck, 2008: 114).

$\mathrm{Al}$ igual que el resto de riesgos globales, el fenómeno de las maras provoca unos riesgos que se pueden caracterizar por la deslocalización - sus causas y efectos no están limitados a un lugar o un espacio geográfico. Una decisión tomada en El Salvador (hogar de la MS-13) puede provocar una escalada de violencia entre bandas en Los Ángeles (EE. UU.). Además, el impacto (el efecto) provocado por la escenificación a través de los medios les otorga un principio de "omnipresencia"-; la incalculabilidad — sus consecuencias son incalculables por definición; se trata de "riesgos hipotéticos" que necesitan ser verificados. En nuestro país la fase de "latencia" nos impide ver más allá del presente y hemos de "imaginar" su posible evolución, haciendo del pronóstico más un "augurio" que una hipótesis fundamentada en hechos objetivos-; y la no compensabilidad - frente a la muerte de menores y jóvenes provocada por la violencia irracional de sus iguales, la lógica de la compensación deja de ser válida y la sustituye el principio de la previsión mediante la prevención y el empeño de anticipar y evitar riesgos cuya existencia aún no está probada-.

Con la sociedad del riesgo mundial se difuminan las categorías de los otros y nosotros, inmigrantes y autóctonos, el fin de nuestra posición de distanciamiento frente a los riesgos. La fuerza de los peligros globales destruye las zonas protegidas tanto internas como internacionales. Bajo estas condiciones, las 
instituciones nacionales (y sus reglas) que tienen por objetivo la identificación y el reconocimiento de los riesgos (las relaciones nacionales de definición) pueden obstaculizar el control transnacional del ir y venir de los peligros. La información de los Estados organizada nacionalmente no fluye hacia los países receptores de riesgos, lo que merma la eficacia en la lucha contra este tipo de organizaciones; la colaboración internacional no es una opción, sino una condición para la buena marcha de las investigaciones.

En España el fenómeno está viviendo una primera fase donde los episodios violentos son esporádicos y su vinculación con la delincuencia es todavía reducida. No obstante, la experiencia vivida en los EE. UU. viene a demostrar el carácter "líquido", el continuo cambio de este tipo de organizaciones. No son organizaciones "sólidas", sino que su morfología se adapta al entorno y muta cuando la situación lo exige. Nacen y se extienden cuando el terreno es "fértil" y adoptan la forma necesaria para su supervivencia. La dinámica de estas agrupaciones se basa en la posibilidad permanente de cambio. Por lo que respecta a nuestro país, los investigadores hablan de "latencia" para indicar la etapa en la que se encuentra este fenómeno social. Las pandillas preocupan, pero no por lo que son, sino por lo que pueden llegar a ser.

El riesgo que hace un momento aún estaba aquí con un semblante determinado, ahora ya está allí y con un rostro totalmente diferente según las culturas, sistemas, regiones del planeta [...]. Es lo líquido de (Bauman), o sea, la transformación permanente, el amontonamiento de riesgos a menudo pasajeros [...]; riesgos que constituyen la ambivalencia e incalculabilidad de la sociedad del riesgo mundial (Beck, 2008: 94).

Los riesgos señalan a la posibilidad futura de ciertos acontecimientos y procesos, hacen presente una situación mundial que (aún) no existe. La categoría de riesgo se refiere por tanto a la realidad discutible de una posibilidad que no es mera especulación pero tampoco una catástrofe efectivamente acaecida. Los riesgos son siempre acontecimientos futuros que es posible que se presenten, que nos amenazan y, puesto que esta amenaza permanente determina nuestras expectativas, invade nuestras mentes y guía nuestros actos [...] (Beck, 2008: 27).

Otro rasgo a tener en cuenta y que inclina la balanza a favor del marco de la teoría critica de la sociedad del riesgo mundial es el hecho que deriva del éxito 
de estas agrupaciones. La victoria de las maras se debe a que no emplean una racionalidad instrumental carente del refugio de los afectos y el calor de la comunidad; por el contrario, proporcionan a sus miembros la identidad perdida, la seguridad y la protección de una organización que pasará a ser su familia. En cambio, la racionalidad instrumental de la primera modernidad que sigue imperando se preocupa principalmente por lo siguiente:

Ésta se mueve exclusivamente por la maximización de la efectividad y la eficiencia. Los afectos, por el contrario, no son cosa suya, como tampoco la 'preocupación por el ser', el propio y el de los demás, que sí forman parte de las experiencias existenciales y transfronterizas clave en la sociedad del riesgo mundial (Beck, 2008: 269).

Una investigación que quiera ofrecer un nivel aceptable de comprensión de este peculiar fenómeno social y conseguir abrir el campo a intervenciones que prevengan sus amenazas ha de abandonar las aguas de la racionalidad instrumental de la etapa industrial para "bucear" en la reflexividad de los riesgos globales. Para analizar estas agrupaciones como nuevas formas sociales, tendremos que emprender el viaje hacia el nuevo paradigma y sumergirnos en el océano de la incertidumbre de la sociedad del riesgo mundial para llegar a una hermenéutica cosmopolita que nos permita comprender la dinámica de los conflictos que dicha sociedad comporta.

\section{Bibliografía}

Andino, Tomás (2006). Las maras en la sombra. Tegucigalpa: UCA.

Bauman, Zygmunt (2000). Modernidad líquida. Buenos Aires: Fondo de Cultura Económica.

Bеск, Ulrich (1986). La sociedad del riesgo. Hacia una nueva modernidad. Barcelona: Paidós.

- (2008). La sociedad del riesgo mundial. En busca de la seguridad perdida. Barcelona: Paidós.

Bourdieu, Pierre (1972). Outline of a Theory of Practice. Cambridge: Cambridge University Press.

Cruz, José M. (2006). Maras y pandillas en Centroamericana. San Salvador: UCA. 
Demoscopía, S. A. (2007). Maras y pandillas, comunidad y policía en Centroamérica. Hallazgos de un estudio integral [en línea]. Disponible en web: $<$ http://www.undp.org.gt/data/publicacion/Maras\%20y\%20pandillas, $\% 20$ comunidad $\% 20$ y $\% 20$ polic $\%$ C3\%ADa $\% 20$ en $\% 20$ centro $\% 20$ am\%C3\%A9rica.pdf>

Falkenburguer, E. y Thale, G. "Maras centroamericanas: Políticas públicas y mejores prácticas". Revista CIDOB d'Afers Internacionals, n. ${ }^{\circ} 81$ (2008), pp. 45-66.

Feixa, Carles (2008). De lóvenes, bandas y tribus. Barcelona: Ariel.

Fernández J. y Ronquillo V. (2009). De los maras a los zetas. México: Ediciones DeBolsillo.

Gallego, Pedro (2008). La mara al desnudo. Málaga: Sepha.

Gramsci, Antonio (2000). Cuadernos de la cárcel. México: ERA.

Hall, S. y Jefferson, T. (2005). Resistance through Rituals: Youth Subcultures in Post War Britain. University of Birmingham.

Hannerz, Ulf (1986). Exploración de la ciudad. Hacia una antropología urbana. México: Fondo de Cultura Económica.

Hedbige, Dick (2002). Subcultura: el significado del estilo. Barcelona: Paidós.

Macionis, John J. y Plummer, Ken (2011). Sociología. Madridः Pearson.

Martel, Roxana (2007). "Las maras salvadoreñas: nuevas formas de espanto y control social”, en J. M. Valenzuela, A. Nateras y R. Reguillo (coords.): Las maras. Identidades juveniles al límite. México: UAM, pp. 83-125.

Martí, Josep. "La presentación social del cuerpo en el contexto de la globalización y la multiculturalidad”. Revista de Dialectología y Tradiciones Populares, vol. LXVII, n. ${ }^{\circ} 1$, enero-junio 2012, pp. 7-18.

Martín, José (2007). “Las maras, un problema sobredimensionado”, en J. M. Valenzuela, A. Nateras y R. Reguillo (coords.): Las maras. Identidades juveniles al límite. México: UAM, pp. 157-186.

Perea, Carlos M. (2007). "Pandillas y sociedad contemporánea”, en J. M. VAlenzuela, A. Nateras y R. Reguillo (coords.): Las maras. Identidades juveniles al límite. México: UAM, pp. 271-206.

Porzio, Laura. "El cuerpo entre la resistencia y la asimilación: Estrategias incorporadas e itinerario corporal de un latin king". Revista de Dialectología y Tradiciones Populares, vol. LXVII, n. ${ }^{\circ}$ 1, enero-junio 2012, pp. 85-114. 
Pujadas, Joan J. (1992). El método biográfico: El uso de las historias de vida en ciencias sociales. Madrid, Centro de Investigaciones Sociológicas (CIS).

Savanije, Win (2007). "Las pandillas transnacionales o maras: violencia urbana en Centroamérica”. Foro Internacional. Vol. XLVII, n. ${ }^{\circ}$, julio-septiembre 2007, pp. 637-659.

Soriano, Juan P. (2008). "Adaptación social de las pandillas juveniles latinoamericanas en España. Pandillas y organizaciones juveniles de la calle". Revista CIDOB d'Afers Internacionals, n. ${ }^{\circ} 81,2008$, pp. 109-137.

Valenzuela, José M. et alii (2007). Las maras. Identidades juveniles al límite. México: UAM.

Wolf, Sonja (2009). "El control de las pandillas en la relación El SalvadorEstados Unidos". Foreign Affairs Latinoamérica, vol. IX, n. ${ }^{\circ}$ 4, octubre-diciembre 2009, pp. 85-86. 